\title{
Subsídios à Tomada de Decisão da Escolha da Modalidade para o Planejamento dos Transportes no Estado do Paraná
}

\author{
Ricardo Silveira Martins \\ José Vicente Caixeta Filho
}

\section{RESUMO}

Os canais de comercialização de grãos e farelo de soja convivem com a separação geográfica entre produção e consumo ou exportação no Estado do Paraná. Nesse sentido, o aprimoramento da oferta dos serviços de transporte é instrumento particularmente interessante na construção da competitividade das commodities, em cujos mercados prevalecem como padrão de concorrência o preço. Esse estudo utilizou modelos de racionalização do uso da infra-estrutura de transporte, com base nos fretes, para balizar a avaliação entre a distribuição modal socialmente desejável e aquela efetivamente observada. Os resultados obtidos sinalizaram para o incremento muito significativo na utilização das ferrovias. Em decorrência do desvio em relação à situação efetivamente observada, sugere-se que haja esforços dos órgãos de planejamento dos transportes para o aprimoramento de outros aspectos associados ao transporte ferroviário, tais como pontualidade, perdas e condições gerais de acondicionamentos, o que talvez tenha mais facilidade de ser implementado, em face da gestão privada das ferrovias paranaenses. Isso poderia fazer convergir interesses particulares dos usuários e interesses públicos.

Palavras-chaves: logística; agronegócio; economia paranaense.

\begin{abstract}
The marketing chain of grains and soybean meal live together with the geographical separation between production and consumption or export in the State of Paraná, Brazil. The improvement of the transport services supply is an important tool in the construction of the competitiveness of the commodities, in whose markets prevails as competition pattern the price. This study used rationalization models about the transport infrastructure, based in freights, to beacon the evaluation socially between the modal distribution desirable and that indeed observed. The obtained results signalled for the quite significant increment in the use of the railroad transportation. Due to the deviation in relation to the situation indeed observed, one suggests that there is the need of efforts associated to the rail transport, such as punctuality, losses and general conditions of packaging, what perhaps has more means of being implemented in face of the deprived administration of the railroads of the State of Paraná. That could converge interests peculiar of the users and public interests.
\end{abstract}

Key words: logistics; agribusiness; economy of Parana. 


\section{INTRODUÇĀO}

O desenvolvimento da agricultura exige infra-estrutura adequada ao escoamento de suas safras. Isto porque, embora os custos de transporte sejam relevantes em qualquer atividade econômica, estes se tornam mais significativos no caso dos produtos agrícolas. Estima-se que a participação dos custos de transporte, no preço final dos produtos agrícolas no atacado, seja mais que duas vezes maior em relação aos produtos manufaturados. Além do mais, a variável preço é importante elemento na construção da competitividade de commodities; conforme Ferraz, Kupfer e Haguenauer (1995), importância esta reforçada pelos cenários agrícolas atuais, que combinam maior abertura e integração regional.

No caso do Brasil, os serviços logísticos, historicamente, não funcionaram bem; isso implicou perda de competitividade para alguns casos no agronegócio. Muitas vezes, a vantagem comparativa na produção não era corroborada pelo acesso do produto ao mercado, em função dos custos incursos na movimentação do produto ao consumidor final, notadamente por deficiências na estrutura de armazéns e por elevados custos de transporte.

No que diz respeito aos transportes, isto acontece em função, basicamente, de dois aspectos: a concentração do transporte de mercadorias no modal rodoviário e investimentos insuficientes, a partir dos anos oitenta, para a manutenção e expansão dos sistemas de transporte em níveis compatíveis com a demanda. Essa é parcela importante do Custo Brasil, reflexo da queda dos investimentos públicos em infra-estrutura, fenômeno que vem ocorrendo desde a década de oitenta.

Algumas medidas têm sido tomadas no sentido de corrigir essas deficiências e podem ser localizadas no programa Brasil em Ação, no Plano Plurianual ou nas estratégias das próprias empresas. Nesse contexto, com base no Plano Nacional de Desestatização, as ferrovias brasileiras foram concedidas às empresas privadas, como forma de reativar essa importante modalidade de transporte, principalmente para granéis agrícolas, como grãos e farelos, proporcionando investimentos que recuperem as condições das vias férreas e ampliem o capital em material rodante.

As hidrovias entram definitivamente na história dos transportes no Brasil. A finalização da hidrovia Tietê-Paraná, e outros empreendimentos hidroviários no Norte, no Sudeste e no Sul permitem vislumbrar um cenário em que os produtos agrícolas e agroindustrializados possam fazer a opção por portos com custos 
mais baixos, e fazer chegar seus produtos a preços menores a centros consumidores nacionais, ou mesmo àqueles centros antes não supridos.

Outras facilidades são as Estações Aduaneiras do Interior (EADI). Essas estações, também conhecidas como portos secos, permitem às empresas exportadoras ou importadoras uma série de vantagens, como otimizar prazos, reduzir custos aduaneiros e até mesmo utilizar serviços completos de logística (em alguns casos). A Receita Federal espera que em 2003, as EADIs possam responder por dois terços do movimento das importações e exportações. As empresas que pretendem continuar suas operações nos portos estão providenciando os terminais privativos, com base na preocupação maior de redução dos custos.

As novidades também estão no campo da multimodalidade. No caso do Brasil, o Plano Plurianual 1996-99 do Governo Federal manifesta a preocupação de ativação de sistemas intermodais, por intermédio do funcionamento eficiente dos diferentes modais. O plano prioriza os corredores de transporte multimodais integrados para fins de integração nacional e competitiva entre as áreas de produção e os centros de consumo do país ou pontos de importação/exportação.

Dessa maneira, as forças da economia globalizada e da concorrência internacional colocaram os serviços logísticos no centro das preocupações acerca da competitividade dos produtos. Para as cadeias do agronegócio, seguramente essas preocupações não são pequenas.

No caso do Estado do Paraná, a problemática da relação entre a adequação da infra-estrutura de transporte e o agronegócio é potenciada por algumas razões. Primeiramente, deve-se considerar a predominância agrícola e agroindustrial na economia local ${ }^{(1)} \mathrm{e}$ a participação desses seus gêneros nas exportações brasileiras. Conforme Magalhães Filho (1974), a economia paranaense está baseada na exportação de produtos primários, com destaque para grãos. Nessas atividades, $\mathrm{o}$ Paraná ocupa papel relevante no conjunto da economia brasileira, tanto por sua participação na oferta quanto por sua rápida resposta aos estímulos de mercado. Por outro lado, a localização das agroindústrias é influenciada por fatores diversos, tais como disponibilidade e qualidade da matéria-prima e da mão-de-obra, bem como pelas facilidades de comercialização da produção (disponibilidade e custo do transporte).

Na situação dos produtores e dos intermediários como tomadores de preços, a tarefa de maior alcance é minimizar custos para ser competitivo. Nesse sentido, convive-se com uma realidade de separação geográfica entre a produção agrícola, a oeste, e as regiões de consumo e exportação, a leste. Enquanto nas regiões Oeste e Sudoeste se produz 50 e $83 \%$, respectivamente, do total da soja e do trigo paranaenses, nelas concentram-se 20,7 e $16 \%$ da capacidade instalada para processamento, respectivamente, de soja e trigo ${ }^{(2)}$. 
A redução dos custos associados aos serviços de transporte conflue no conhecimento dos custos e de outros aspectos qualitativos, ligados às modalidades de transporte e demais opções intermodais, bem como do potencial de aprimoramento da qualidade dos serviços prestados e do potencial de rebaixamento desses custos.

Assim, o objetivo geral do presente estudo ${ }^{(3)}$ é avaliar o transporte de milho, soja, e farelo de soja no Estado do Paraná, com vistas à avaliação de aspectos inerentes às modalidades disponíveis, como forma de fornecer subsídios aos agentes demandantes dos serviços.

Na próxima seção será apresentada a infra-estrutura de transporte no Estado do Paraná, seguida pela caracterização geral, por origem-destino dos fluxos dos produtos em apreço. As seções em seqüência apresentam modelos de otimização aplicados com os objetivos de se conhecer a distribuição modal minimizadora de custos, conforme alguns cenários, e a avaliação geral da viabilidade do transporte intermodal, a partir das principais rotas.

\section{Aspectos Gerais e Infra-Estrutura de Transporte no Estado do PARANÁ}

O Estado do Paraná contribui historicamente com cerca de $25 \%$ da produção brasileira de grãos. A safra nacional de grãos de 1994/95 foi de 81 milhões de toneladas, sendo que os produtos milho, soja e trigo representaram $80 \%$ desse total e ocuparam 38,5 milhões de hectares (CONAB, 1996). O Estado liderou a produção nacional desses produtos nesta safra, tendo atingido para milho, soja e trigo, respectivamente, $24,5 \%, 21,4 \%$ e $68,7 \%$ do total nacional.

Para efeito deste estudo, procedeu-se ao zoneamento do Estado, para a identificação de pólos econômicos, pressupondo-se que nestes se concentram empresas de comercialização de produtos agrícolas e empresas agroindustriais. Para estudos dessa natureza, a identificação de pólos significa concentração das atividades econômicas, em sentido geral, implicando a geração de fluxos mais consistentes e significativos de transporte. Para tal, segue-se a metodologia da regionalização adotada pelo Instituto Brasileiro de Geografia e Estatística (IBGE), conforme documentado na FIBGE (1987), e apresentado na Figura 1. 


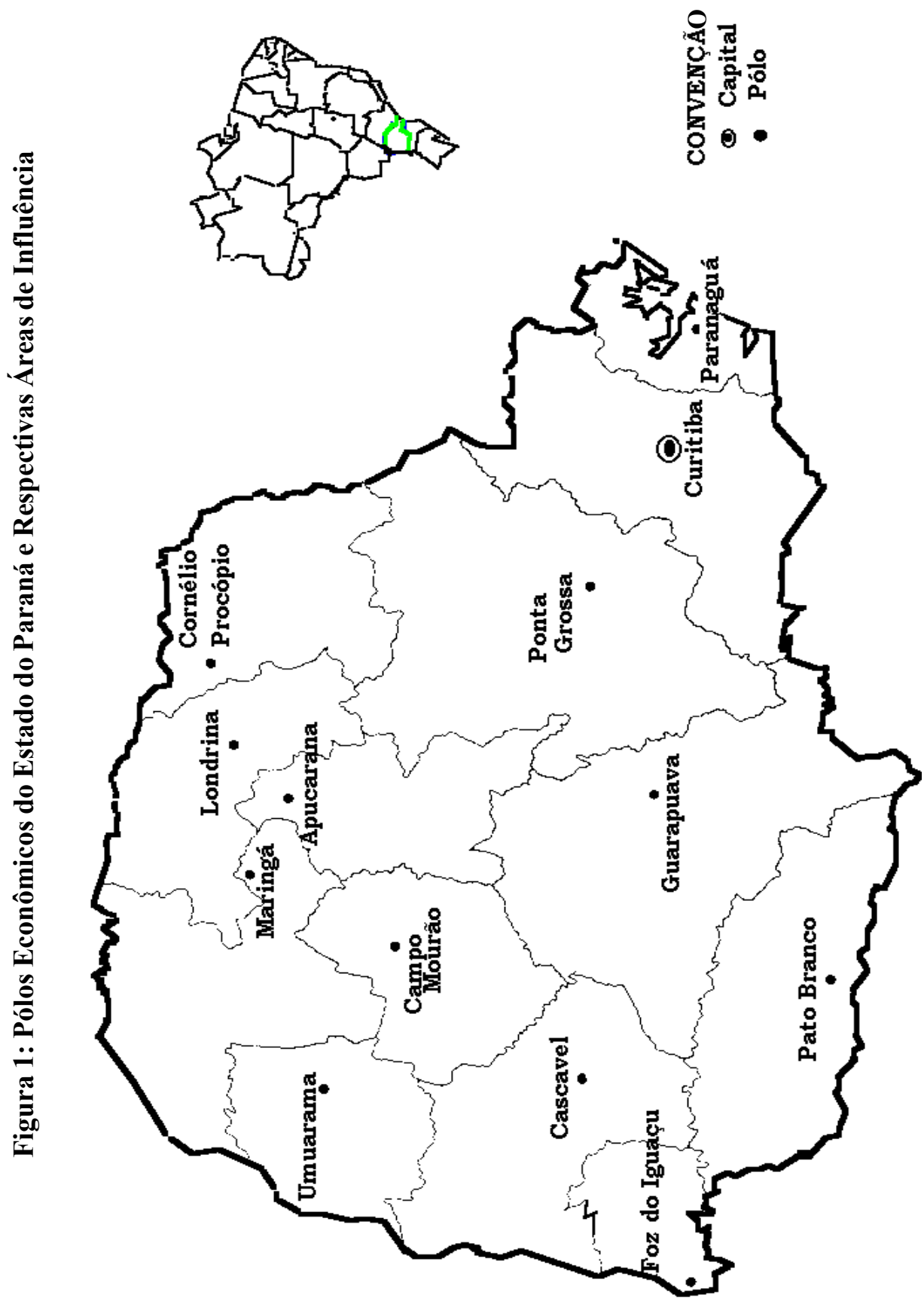




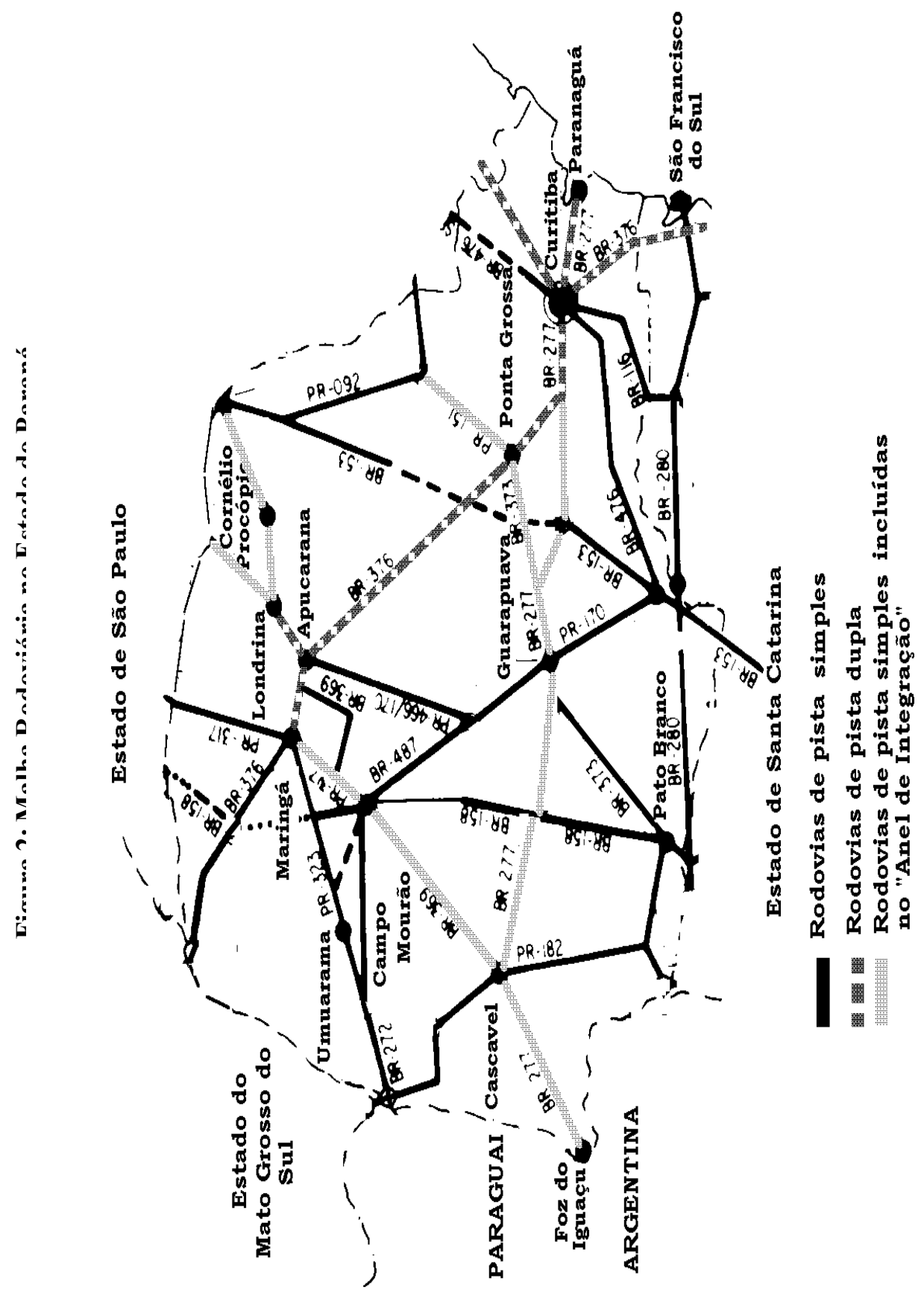




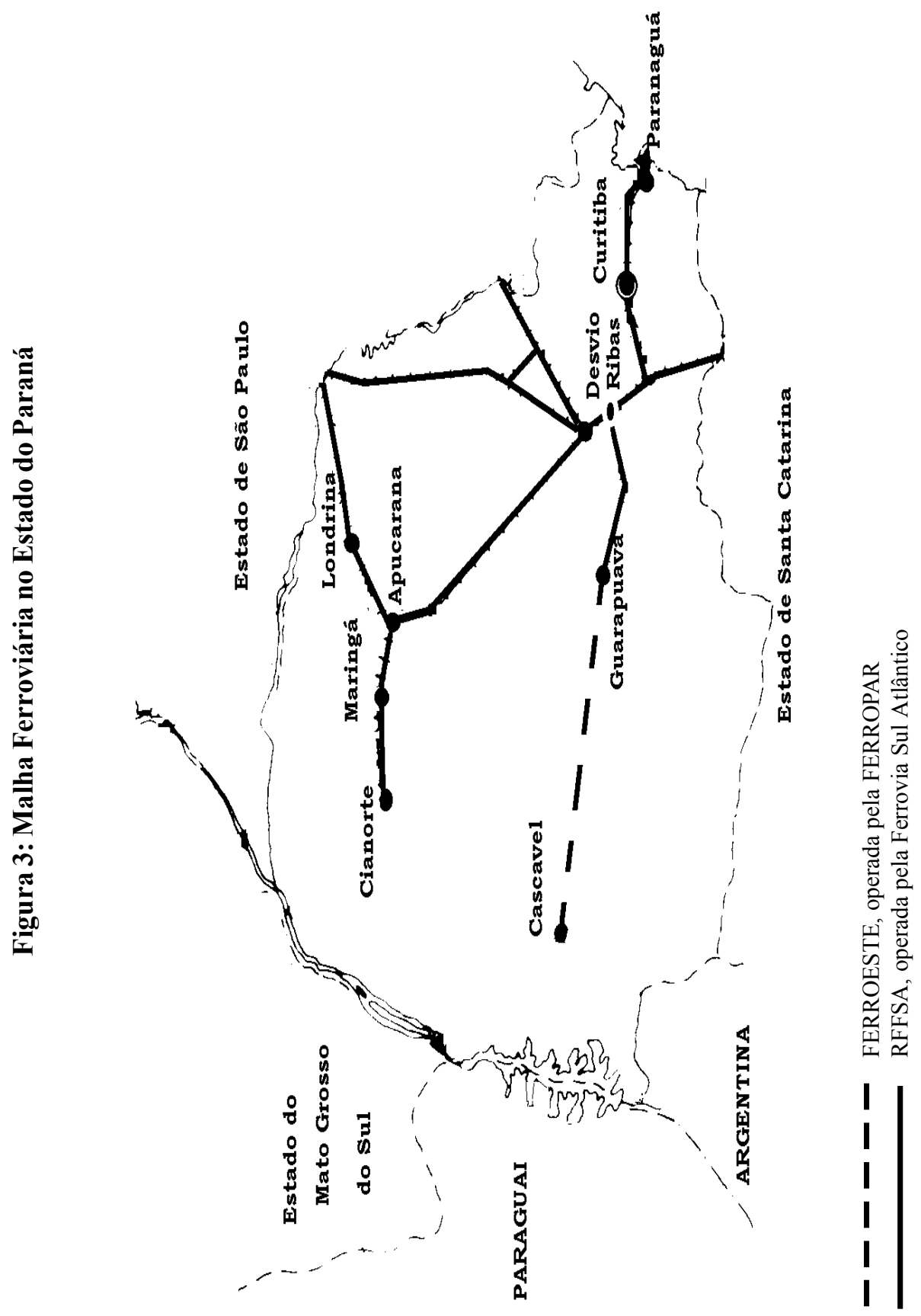


No Estado do Paraná, predomina a modalidade rodoviária de transporte. Segundo a Secretaria dos Transportes (1996), somando-se as redes rodoviárias federal, estadual e municipal, o sistema atinge $40.200 \mathrm{~km}$ e cerca de $2.500 \mathrm{~km}$ de extensão de vias férreas, e sem alternativas de transporte hidroviário. Do sistema rodoviário total, $2.029 \mathrm{~km}$ compõem o programa de concessão de rodovias do Estado, intitulado Anel de Integração, que visa à melhoria da qualidade das rodovias e à prestação de serviços, tais como melhor conservação e duplicação das vias, contornos de cidades, postos de pesagem e postos médicos (Secretaria de Transportes, 1996). A Figura 2 identifica as rodovias que interligam os pólos desse estudo.

Por sua vez, as ferrovias paranaenses concentram-se na parte oriental do Estado, tendo nítido caráter de escoadouro da produção agrícola da região Norte. A Figura 3 apresenta as linhas principais e os ramais que compõem a malha ferroviária paranaense. Observou-se recentemente a entrada em operação da FERROESTE: é a primeira iniciativa para desconcentrar a malha, incrementando o transporte ferroviário na parte central em direção ao oeste. Toda essa malha foi repassada à administração privada, o que pode reverter em utilização mais intensiva da infra-estrutura existente e em novos projetos ferroviários.

O porto de Paranaguá complementa a infra-estrutura de transporte do Estado. Localizado em ponto estratégico, esse porto tem como área de influência o Estado do Paraná, e porções de Santa Catarina, Rio Grande do Sul, Mato Grosso do Sul e São Paulo.

\section{Características dos Fluxos de Origem-Destino}

Os fluxos dos produtos em estudo foram estimados por matrizes de origemdestino em Martins (1998). Foi estimado um fluxo total dos produtos de 12.980.096 t entre os pólos, o que merece algumas observações. Inicialmente, cabe destacar que os pólos aos quais se direcionou um volume mais expressivo de grãos e farelos foram aqueles onde se concentra parcela significativa da agroindústria processadora e que também, para efeito desse estudo, se referem aos pontos de saída do Estado de acordo com as rotas utilizadas, Ponta Grossa e Londrina, e ao porto de Paranaguá, com destino aos mercados externos, com 8,836 milhões de t. Com relação à produção, destacam-se os pólos de Ponta Grossa, Campo Mourão, Cascavel, Cornélio Procópio, Pato Branco, Guarapuava e Foz do Iguaçu. A observação das quantidades produzidas e consumidas de grãos e farelos no Estado do Paraná permite identificar dois grandes centros, a partir dos quais se originam os fluxos mais significativos de grãos no Estado, sendo um nas regiões Oeste (Cas- 
cavel, Campo Mourão e Foz do Iguaçu) e Sudoeste (Pato Branco) e outro no Norte (Cornélio Procópio, Londrina, Apucarana e Maringá). Cabe destacar que a região Norte, embora seja grande produtora, também consome parcela significativa de sua produção, pelo adensamento urbano e demográfico.

Esta observação permite também identificar o perfil do fluxo de grãos no Estado do Paraná. Em linhas gerais, as regiões Oeste e Sudoeste abastecem a agroindústria processadora localizada em Curitiba e Ponta Grossa (região Leste), com pequena capacidade instalada de processamento. Outra parcela significativa, no caso da soja, destina-se à exportação em grão pelo porto de Paranaguá. Por sua vez, no caso desse produto, embora a região Norte do Estado possua significativa capacidade de processamento de soja, os fluxos do produto são expressivos em virtude dos volumes que vêm de outras unidades da Federação, para utilizar o porto exportador de Paranaguá. É também significativo o volume de farelos que percorre a mesma trajetória, composto pela produção da região, e pela parcela que adentra o território paranaense pelos pólos localizados na região Norte. Registram-se, também, significativos fluxos de milho e trigo para outros Estados brasileiros.

Este agregado de informações clareia a configuração dos fluxos no Estado, no que se refere a milho, soja, e farelo de soja. Em síntese, estes gêneros são produzidos nas regiões Norte, Oeste e Sudoeste e absorvidos pela agroindústria das regiões Leste e Norte, por outros Estados brasileiros, principalmente aqueles pertencentes às regiões Sudeste, Nordeste e Centro-Oeste e, majoritariamente, pelo porto de Paranaguá (64\% do destino dos fluxos).

\section{Racionalização do Transporte de Grãos e Farelo de Soja no Estado do Paraná}

A avaliação da modalidade de custo mínimo para o transporte de grãos e farelo de soja no Estado do Paraná está baseada num modelo de programação linear. O objetivo da utilização desse modelo é obter a distribuição modal ótima dos fluxos de produtos entre os pólos, de modo que se minimize o custo total de transporte (Z) no Paraná. Para tal, foi utilizado o software General Algebraic Modeling System - GAMS (Brooke, Kendrick e Meerans, 1996), aplicado à seguinte estrutura matemática:

$$
\operatorname{Min} \quad Z=\sum_{i=1}^{13} \sum_{j=1}^{13}\left[\left(F R_{i j} \cdot T R_{i j}\right)+\left(F F_{i j} \cdot T F_{i j}\right)\right]
$$


sujeito à

$$
\begin{gathered}
T R_{i j}+T F_{i j}=T_{i j}, \quad \text { para todo } i, j \\
T F_{i j} \leq C_{i j}
\end{gathered}
$$

sendo:

$Z=$ função de custo total de transporte do fluxo de grãos e farelo de soja;

$F R_{i j}=$ frete rodoviário (em US\$/t) entre os pólos $i$ e $j$;

$T R_{i j}=$ quantidade transportada pela modalidade rodoviária $(t)$ entre os pólos $i$ e $j$;

$F F_{i j}=$ frete ferroviário (em US\$/t) entre os pólos $i$ e $j$;

$T F_{i j}=$ quantidade transportada pela modalidade ferroviária $(t)$ entre os pólos $i$ e $j$

$T_{i j}=$ fluxos de grãos e farelo de soja com origem em $i$ e destino em $j$ (matrizes $\mathrm{O} / \mathrm{D}$ estimadas);

$C_{i j}=$ capacidade de tráfego dos produtos nas ferrovias.

As equações 2 e 3 são as restrições do modelo. Essas restrições dizem respeito ao total de produto a ser transportado e à capacidade de tráfego nas ferrovias do Estado. Quanto a esta última restrição, as informações foram obtidas com as empresas operadoras do transporte ferroviário no Estado, a Ferrovia Sul Atlântico (FSA) e a Ferrovia Paraná (FERROPAR), com base na capacidade operacional estática das ferrovias em 1977 e na participação histórica desses produtos na produção de carga das empresas.

Assim, nas restrições foram incorporadas estas limitações de capacidade das ferrovias, respeitando-se os fluxos entre os pólos e localização geográfica destes. Desta maneira, de forma geral, as restrições foram:

· Cornélio Procópio/Londrina/Maringá/Apucarana/Paranaguá = 8.823.168 t/ ano;

· Cascavel/Guarapuava/Ponta Grossa/Curitiba/ Paranaguá = 993.600 t/ano; 
· Todos os pólos - Paranaguá = 11.128.320 t/ano.

Os valores utilizados para os fretes rodoviários e ferroviários foram estimados em Martins (1998), e referem-se aos fretes efetivamente praticados no Estado do Paraná, quando esta informação estava disponível, e por estimativas por funções lineares, quando se utilizavam essas informações para se chegar aos fretes estimados.

\section{Distribuição Ótima entre as Modalidades Rodoviária e Ferroviária no Transporte de Grăos e Farelo de Soja no Estado do Paraná}

Foram explorados cenários que dizem respeito aos fluxos estimados para 1995, para serem movimentados dentro da infra-estrutura de transporte existente e considerando-se a expansão proporcionada pela FERROESTE.

Uma análise importante associada à escolha da modalidade que minimiza $\mathrm{o}$ custo total de transporte no Estado diz respeito ao custo de oportunidade. Este é um valor monetário que informa que a eventual utilização de uma modalidade preterida pelo modelo implicaria aumento no custo total, para cada tonelada transportada.

\section{Situação 1: Distribuição Modal Ótima com a Infra-estrutura Disponível em 1995}

Nesta situação, objetivou-se determinar a alocação modal ótima dos fluxos estimados, aquela que minimiza os custos totais de transporte de grãos e farelo de soja no Estado do Paraná, dentro das modalidades de transporte efetivamente disponibilizadas em 1995.

Nenhuma restrição incidente sobre a capacidade de tráfego das ferrovias foi atuante, o que quer dizer que a situação ótima não apontou problemas de capacidade das ferrovias paranaenses. No trecho Cornélio Procópio-Paranaguá, o modelo priorizou o transporte rodoviário nos fluxos originados em Cornélio Procópio e destinados a Ponta Grossa, Curitiba e Paranaguá, e aqueles vindos de Londrina para Paranaguá. Ao transporte ferroviário de Cornélio Procópio para Ponta Grossa associou-se o custo de oportunidade de US\$0,76/t; para Curitiba, US\$9,30/t; e para Paranaguá, US\$1,71/t. Isto significa dizer que a cada tonelada de produto transportada por esta modalidade implicaria aumentos nos gastos totais com transporte no Estado nos respectivos valores.

Utilizar o transporte ferroviário, a partir de Londrina, implicaria ocorrência de custo de oportunidade de US\$3,38/t. Esta situação alterava-se em favor do trans- 
porte ferroviário, a partir da equiparação dos fretes associados às diferentes modalidades.

O trecho Guarapuava-Ponta Grossa-Curitiba também apresentou ociosidade de cerca de $11 \%$. Apesar do modelo ter alocado toda a carga agrícola de interesse neste estudo nas ferrovias, isso deve-se ao fato de não haver volume suficiente com origem em Guarapuava e destino a Ponta Grossa, Curitiba e Paranaguá, para esgotar a capacidade disponível.

Por outro lado, o grande fluxo de transporte ferroviário nesta situação estaria concentrado na ligação Maringá/Ponta Grossa-Paranaguá, situação atualmente observada no Estado. Parte significativa deste fluxo ferroviário origina-se em Maringá, como resultado do transbordo de produtos com pontos de origem em outros Estados.

Comparativamente ao tráfego efetivamente ocorrido, o modelo sinalizou para o uso mais intensivo do transporte ferroviário como forma de diminuir os custos totais de transporte de grãos e farelo de soja no Paraná. Os resultados implicaram um acréscimo de $27 \%$ no volume do transporte ferroviário para os produtos em apreço dentro do Estado, chegando a um aumento de $40 \%$ no tráfego ferroviário destinado a Paranaguá.

\section{Situação 2: Distribuição Modal Ótima, Considerando-se que a Ferroeste Estivesse Operando em 1995}

Quando se considera a FERROESTE operando em 1995, observa-se pouca diferenciação em relação à situação em que esta ferrovia inexistia, expressa pela redução de custo de $0,014 \%$. O aumento da quantidade do transporte ferroviário deveu-se exclusivamente ao preenchimento da capacidade da alternativa ferroviária, passando a ocorrer o transporte de 109 mil toneladas de Cascavel com destino a Paranaguá.

\section{Situação 3: Distribuição Modal Ótima, Considerando-se que a Ferroeste Estivesse Operando em 1995, com Correção do Estran- gulamento a partir de Guarapuava}

Atualmente, a FERROESTE conta com estrangulamento significativo. No trecho Cascavel-Guarapuava existe capacidade de tráfego de 2.649.600 t/ano, enquanto no próximo segmento, Guarapuava-Ponta Grossa (Estação Engenheiro Gutierrez), esta capacidade cai para 993.600 t/ano. Esse estrangulamento é crítico para a utilização do transporte ferroviário e a relevância de sua correção foi destacada nos anos setenta, pelo estudo de Wright (1980), que acenou para a reconstrução do trecho ou mesmo para a construção de nova linha. 
Dessa maneira, explorou-se uma situação em que este estrangulamento estivesse corrigido, mantendo a capacidade de toda extensão (Cascavel-GuarapuavaPonta Grossa-Curitiba-Paranaguá) em 2.649.600 t/ano. Essa correção implicou redução no custo total de transporte no Estado de $0,12 \%$, equivalendo esta diferença a US $\$ 314.830,83$.

A restrição referente ao trecho acima não foi atuante, ficando com uma folga de 702 mil t/ano. O aumento da capacidade não alterou a distribuição dos fluxos com origem em Guarapuava, apenas a realocação modal para o transporte ferroviário de 954 mil t/ano originárias em Cascavel, passando por essa modalidade o volume total com origem nesse pólo.

\section{Transporte Intermodal de Grãos e Farelo de Soja no Estado do Paraná}

A importância da análise da opção intermodal está consubstanciada na perspectiva mais ampla, que tem norteado o planejamento de transportes das nações, de redução de custos em busca da competitividade nos mercados internacionais. Conforme Lieb (1978), por causa de características diferentes entre os modais alternativos, como custos e outros aspectos qualitativos, pode ser economicamente desejável que, entre a origem e o destino de uma determinada mercadoria, se lance mão de mais que uma modalidade de transporte, utilizando as vantagens inerentes a cada uma delas, o que resulta em serviço de menor custo e/ou de melhor qualidade.

A complementação entre as modalidades de transporte envolvidas num sistema intermodal implicará atividades de transbordo, isto é, recursos humanos e equipamentos para transferir as mercadorias de um meio de transporte para outro.

Segundo Novaes (1978), na formulação do problema de transbordo, a diferença básica com relação ao modelo anterior é que regiões produtoras e consumidoras também possam participar com relevantes volumes relativos às atividades de transbordo. Neste sentido, pode-se até chegar à situação de uma região inexpressiva, em termos de produção e consumo, mas que se transforma em importante centro de transferência intermodal de mercadorias. No caso deste estudo, apesar de sua importância no consumo e produção, verificou-se que o pólo Maringá mantém essa característica muito evidente, pelos fluxos apresentados por causa da localização dos terminais de integração intermodal rodovia-RFFSA.

O modelo para a avaliação da alternativa de transporte de custo mínimo para o 
transporte de grãos e farelo de soja no Estado do Paraná é o mesmo da seção anterior, acrescido das alternativas intermodais.

Foram feitas análises dos fretes em dois níveis distintos. No primeiro, na perspectiva do usuário, procurou-se determinar o percurso de custo mínimo para as rotas. Noutro nível, desenvolveu-se a análise de sensibilidade dos fretes intermodais, com o objetivo de identificar seus níveis de competitividade na perspectiva da racionalidade do modelo, que é a distribuição entre as modalidades que minimizam o custo total de transporte, na condição ceteris paribus, isto é, quando apenas o valor do frete intermodal de determinada rota variava.

Os valores de frete pemanecem aqueles estimados por Martins (1998). Quanto às informações que dizem respeito aos custos de transbordo, foram explorados diferentes valores. Foi usado o valor de US $\$ 1,50 / t$, conforme consultas feitas às empresas prestadoras do serviço no Paraná, nos pólos de Londrina, Ponta Grossa, Cascavel e Maringá, valor este também utilizado por Oliveira (1996). Utilizou-se também US\$1,07/t como custo de transbordo, conforme utilizado em GEIPOT (1997), prevendo alguns avanços tecnológicos que permitam a redução do custo do serviço para o ano 2000.

Ainda, foram simuladas situações que contemplavam apenas uma operação de transbordo entre pares de origem-destino, dada uma distância máxima percorrida de $700 \mathrm{~km}$.

\section{Intermodalidade no Transporte de Grãos e Farelo de Soja no Paraná}

O Paraná mantém algumas características importantes no que diz respeito aos fluxos de grãos e farelo de soja. Por um lado, o Estado direciona grande parte de sua produção para o comércio exterior. Por outro, fluxos significativos de produtos provenientes de outras unidades da Federação são exportados pelo porto de Paranaguá. Além do mais, dado o caráter historicamente superavitário da produção paranaense, seus produtos direcionam-se para as regiões Sudeste e Nordeste, principalmente para fins de abastecimento interno. Assim, foram selecionadas rotas que espelhassem esta realidade, sendo algumas típicas de exportação e outras de abastecimento interno.

Cabe salientar que para o caso dessas duas últimas rotas, com destino a São Paulo, apenas serão aventadas hipóteses de percursos e pontos de transbordo dentro do território paranaense devido às limitações dos objetivos deste estudo. 


\section{Rotas de Exportação}

\section{Campo Mourão - Paranaguá}

Entre as alternativas disponíveis na atualidade, obteve-se o menor frete com a modalidade rodoviária, o que coincidiu com a rota utilizada. Para atingir o destino em Paranaguá, os produtos originados em Campo Mourão são transportados pela BR-487 até Guarapuava, integralizando o percurso pela BR-277. O uso da alternativa intermodal de menor custo foi rodo-ferroviária, apontando Guarapuava como ponto de transbordo. A utilização dessa alternativa implicava um custo de oportunidade de US $\$ 1,85 / \mathrm{t}$, valor associado ao aumento nos gastos totais com transporte para cada tonelada de produto movimentada por esta opção. Isso equivaleria a um acréscimo de $8 \%$ no custo de transporte para este par origemdestino.

No modelo global de competitividade entre as modalidades, foram analisadas as situações de intermodalidade rodo-ferroviária com pontos de transbordo em Maringá e Guarapuava. Para o transbordo em Maringá, a alternativa intermodal foi escolhida pelo modelo, quando se igualava seu custo ao frete de menor valor para as situações em 1995, US\$23,34/t, referente ao transporte rodoviário. A escolha da intermodalidade implicava aumento na utilização do trecho ferroviário a partir de Maringá, não provocando redistribuição na alocação anterior dos fluxos entre as modalidades e implicando um custo de oportunidade muito próximo de zero para o uso do transporte rodoviário.

Mantida a atual capacidade de tráfego, o uso da alternativa intermodal com transbordo em Guarapuava implicou custo de oportunidade de US $\$ 0,33 /$ t. Houve atribuição de fluxo intermodal na rota nessa situação, quando o frete rodo-ferroviário se fixou em US $\$ 23,00 / \mathrm{t}$, distribuindo as quantidades a serem transportadas com a opção rodoviária e eliminando o fluxo ferroviário com origem em Cascavel e destino a Paranaguá.

\section{Cascavel - Paranaguá}

A entrada em operação da FERROESTE permitirá, como demonstrado, uma opção de transporte mais barata para usuários dessa rota; mas pôde-se observar que as alternativas unimodais rodoviária e ferroviária apresentaram estreita concorrência. $\mathrm{O}$ custo de oportunidade de US $\$ 0,33 / t$ para a modalidade rodoviária evidencia esta competição; considerando-se novas tecnologias de transbordo, que possam reduzir o custo dessa operação, a alternativa intermodal ferro-rodoviária, com transbordo em Guarapuava, passa a apresentar resultados interessantes, dado o custo de oportunidade associado a esta opção de US\$0,29/t. Nessa situa- 
ção, pode-se dizer que o usuário tem as alternativas unimodais rodoviária e ferroviária e intermodal com fretes semelhantes. Nessa condição, a escolha poderá ser direcionada por variáveis qualitativas, que dizem respeito à qualidade e à confiabilidade do serviço prestado.

Esta alternativa intermodal não é pertinente às condições projetadas para a FERROESTE. Os terminais de carga/descarga estão localizados em Cascavel; em Guarapuava há apenas a possibilidade de transbordo rodo-ferroviário, e não a alternativa acima descrita, conforme FERROESTE (1996) e GEIPOT (1997).

Assim, não foram avaliadas alternativas de intermodalidade para essa rota. Por um lado, essa impossibilidade não justificaria a exploração da opção ferro-rodoviária com transbordo em Guarapuava. Por outro, essa opção com transbordo em Ponta Grossa apresentou um custo relativamente elevado, 37\% superior, não sinalizando para uma possibilidade de queda tão drástica no custo total, o que, se acontecesse, provavelmente teria comportamento parecido nas outras alternativas. Além do mais, explorar opções rodo-ferroviárias não resolve o problema da pouca utilização do trecho da FERROESTE, Cascavel-Guarapuava, conforme destacado na seção anterior.

\section{Umuarama - Paranaguá}

Embora não seja importante pólo produtor de grãos e farelo de soja no Paraná, a inclusão do pólo de Umuarama justifica-se pelo fato de inserir-se nele o município de Guaíra, ponto de entrada no Paraná, em função da conclusão da ponte sobre o rio Paraná e da localização do terminal intermodal de cargas da hidrovia Tietê-Paraná.

A alternativa unimodal rodoviária, acessando Paranaguá pela BR-277 a partir de Cascavel, é a alternativa de menor custo e coincide com a rota usualmente utilizada; mas o custo de oportunidade de US\$0,66/t da alternativa intermodal rodo-ferroviária, com transbordo em Maringá, sinaliza para um ambiente de concorrência, como reflexo de ligeiras quedas no frete rodoviário Umuarama-Maringá e ferroviário Maringá-Paranaguá.

Considerando-se como ponto de transbordo em Maringá, o transporte intermodal rodo-ferroviário foi escolhido pelo modelo dentro da perspectiva da utilização da infra-estrutura de transporte que incorra no custo total mínimo. Igualando-se o frete intermodal ao rodoviário de US\$28,13/t, a opção intermodal foi sinalizada como a mais racional na perspectiva da infra-estrutura de transporte no Estado, implicando utilização da capacidade do trecho ferroviário a partir de Maringá e um custo de oportunidade nulo para o caso de se utilizar o transporte rodoviário via Cascavel. 
Equiparar o frete intermodal à alternativa de menor custo nos cenários diversos não produziu resultados satisfatórios para o transbordo em Cascavel, em termos da racionalidade do modelo. Para 1995, o frete intermodal rodo-ferroviário a US\$28,13/t não foi competitivo em face da opção rodoviária de mesmo valor, implicando custo de oportunidade de US $\$ 0,30 / t$, uma vez que a capacidade do trecho Cascavel-Guarapuava-Paranaguá se encontrava plenamente utilizada. A escolha do transporte intermodal ocorreu com o frete a US $\$ 27,79 /$, implicando extinção do fluxo ferroviário com origem em Cascavel e destino a Paranaguá. Aumentando-se a capacidade da ferrovia entre Guarapuava e Paranaguá, possibilitada pela correção do estrangulamento existente, o transporte intermodal passa a ser escolhido pelo modelo, implicando custo de oportunidade nulo para a opção rodoviária e apenas aumento da utilização da capacidade do transporte ferroviário.

\section{Foz do Iguaçu - Paranaguá}

Embora em Foz do Iguaçu não seja produzida parcela tão expressiva da produção de grãos e farelo de soja no Estado, sua inclusão no estudo deve-se aos fluxos decorrentes do acordo do MERCOSUL.

Utilizando-se a infra-estrutura de transporte disponível atualmente, o transporte pela modalidade rodoviária, com origem em Foz do Iguaçu e destino a Paranaguá, demonstrou ser a alternativa de menor custo, o que coincide com o percurso praticado. A alternativa intermodal que apresentou melhor resultado foi a rodo-ferroviária, com transbordo em Guarapuava, implicando um custo $6,5 \%$ maior.

Explorando-se a possibilidade de expansão do ramal Cascavel-Foz do Iguaçu, conforme recente anúncio da extensão da FERROESTE, feito pelo Governo Estadual (Monteiro, 1997), as alternativas unimodais rodoviária e ferroviária passam a ter o caráter de concorrentes. Prevalece ligeira vantagem para a modalidade rodoviária, dada pelo custo de oportunidade de US\$0,11/t para a ocorrência do transporte ferroviário. Com melhora na tecnologia de transbordo, a alternativa intermodal ferro-rodoviária, com transbordo em Guarapuava, com custo de oportunidade de US $\$ 0,96 / t$, passa a ser concorrente, embora se deva ressaltar a inexistência atual desta possibilidade.

Na perspectiva da minimização dos custos totais de transporte no Paraná, a intermodalidade foi abordada na rota Foz do Iguaçu-Paranaguá pela opção rodoferroviária, com transbordo em Guarapuava. Ao frete de US\$28,97/t, apenas foi escolhida na situação dos fluxos referentes ao ano de 1995, com correção do estrangulamento. Sem esta correção, ao transporte intermodal imputava-se um custo de oportunidade de US $\$ 0,33 / \mathrm{t}$ no período. O transporte intermodal foi 
escolhido neste caso, quando o frete baixou a US $\$ 28,63 / \mathrm{t}$, quando dividiu com o modal rodoviário a quantidade a ser transportada, implicando extinção do fluxo ferroviário com origem em Cascavel e destino a Paranaguá.

\section{Rotas de Abastecimento Interno}

\section{Pato Branco - Paranaguá}

Atualmente, não existe ramal ferroviário até Pato Branco. Por isso as alternativas disponíveis são a unimodal rodoviária e intermodais, rodo-ferroviárias, com transbordo em Guarapuava, Ponta Grossa e Curitiba.

A alternativa de transporte de menor custo foi a unimodal rodoviária, coincidindo com o percurso utilizado normalmente, pelas BRs-373 e 277. A opção intermodal rodo-ferroviária com transbordo em Guarapuava apresentou-se como a segunda melhor opção, associada a um custo de oportunidade que implicaria aumento de cerca de $10 \%$ no frete.

A opção rodo-ferroviária com transbordo em Guarapuava foi escolhida pelo modelo em algumas ocasiões. Ao frete de US $\$ 21,44 / \mathrm{t}$, igual ao rodoviário, com ou sem correção do estrangulamento a partir de Guarapuava, o modelo sinalizou para a racionalidade da opção em conjunto com o transporte rodoviário. A atribuição ao transporte intermodal de $28 \%$ do fluxo potencial implicou exclusão do transporte ferroviário no trecho Cascavel-Guarapuava. Esta substituição não se verificou, quando se explorou o mesmo cenário com correção do estrangulamento.

\section{Pato Branco - São Paulo}

Foram avaliadas alternativas tendo como ponto de origem o pólo de Pato Branco e destino a cidade de São Paulo. O destino justifica-se por sua importância como centro consumidor brasileiro.

Atualmente está disponível a alternativa unimodal, rodoviária, e intermodais rodo-ferroviária, com transbordo em Guarapuava, Ponta Grossa e Curitiba. A rota Pato Branco-São Paulo apresentou resultados muito diferentes no que diz respeito a percursos de menor custo, sob diversas condições. O percurso de menor custo sinalizou para uma competição bem acirrada entre as opções rodoviária, efetivamente utilizada, e rodo-ferroviária, com transbordo em Ponta Grossa. Essa diferença foi de US $\$ 0,10 / t$ no custo de oportunidade da alternativa rodoviária; a diferença aumenta, quando melhora a tecnologia da operação de transbordo, refletida na diminuição do custo. 


\section{Foz do Iguaçu - São Paulo}

A inclusão desta rota no estudo visa a avaliar o percurso de menor custo para fluxos do MERCOSUL, com mais ênfase para o milho importado da Argentina com vistas ao abastecimento do mercado interno brasileiro. Para isso, dispõe-se atualmente das alternativas unimodais rodoviária via Londrina e via Ponta Grossa, e das alternativas intermodais, rodo-ferroviária, com pontos de transbordo em Maringá, Londrina, Guarapuava e Ponta Grossa.

Dentro das condições proporcionadas pela infra-estrutura atualmente disponível, o percurso de menor custo sinalizou para uma competição bem acirrada entre as opções rodoviária, via Ponta Grossa, e rodo-ferroviária, com transbordo em Ponta Grossa. Essa diferença refletiu-se num custo de oportunidade de US $\$ 0,10 /$ $\mathrm{t}$ desta segunda alternativa, e aumenta para US $\$ 0,53 / \mathrm{t}$ com a possibilidade de melhoria na tecnologia da operação de transbordo.

O percurso efetivamente utilizado, via rodoviária, pelas BRs-277 (até Cascavel) e 369, e a opção rodo-ferroviária, via Londrina, apresentou resultados interessantes, dado o acréscimo de custo, na faixa dos $3,3 \%$, e pelo fato de esta última não ser um percurso convencional; ou seja, há algumas alternativas de transporte com custos competitivos, se a origem é Foz do Iguaçu e o destino São Paulo.

\section{Considerações Finals}

Os resultados obtidos nesse estudo sinalizaram para o fato de que a matriz de transporte para grãos e farelo de soja no Estado do Paraná pode ser significativamente modificada pelo incremento na utilização do transporte ferroviário. Partindo-se de uma situação efetivamente observada em 1995, quando as ferrovias se responsabilizaram por $35,07 \%$ do total transportado dos produtos em apreço, este percentual poderia atingir 44 pontos, somente pela distribuição modal que racionaliza o uso da infra-estrutura de transporte existente (Situação 1).

Estando em operação, a FERROESTE poderia contribuir para maior racionalização do transporte no Paraná; o estrangulamento após Guarapuava compromete esta contribuição (Situação 2). Uma vez corrigido esse estrangulamento, a movimentação de grãos e farelo de soja, em termos ótimos, poderia ser feita majoritariamente por ferrovia (Situação 3).

Esses resultados soam como contraditórios à primeira vista. É como se dissesse que os usuários estão preferindo pagar custos mais altos, associados ao transporte rodoviário; no ato da escolha da modalidade para o transporte de mercadorias, 
além do preço, os usuários avaliam outros aspectos, tais como pontualidade, perdas e condições gerais de acondicionamento.

Nesse sentido, aos olhos dos órgãos de planejamento dos transportes cabem esforços para aprimorar os serviços do transporte ferroviário no Estado do Paraná. Esse aprimoramento deverá refletir-se na maior utilização do transporte ferroviário e talvez tenha mais facilidade de ser implementado em face da gestão privada das ferrovias paranaenses. Como se pôde observar ao longo desse trabalho, atitudes como estas poderiam fazer convergir interesses particulares dos usuários e interesses públicos, conforme se sinalizou pelos resultados dos modelos de racionalização.

Procedeu-se, também, à avaliação da utilização do transporte intermodal para a movimentação de grãos e farelos de soja no Estado do Paraná. Foram identificadas as rotas de maior fluxo, classificadas entre aquelas de exportação e de abastecimento interno.

O modelo avaliou estas possibilidades dentro de duas óticas diferentes. Na primeira, buscava-se analisar o frete intermodal comparativamente às alternativas de transporte, visando à identificação do percurso de menor custo entre pares de origem-destino, que atuaria como sinal para os demandantes dos serviços de transporte. Numa outra ótica, objetivou-se identificar os patamares de fretes intermodais para as rotas selecionadas, que seriam escolhidos pelo modelo global de utilização racional das modalidades, cuja finalidade é encontrar a distribuição modal que minimiza os custos de transporte de grãos e farelo de soja no Estado do Paraná.

Na primeira ótica, pode-se dizer que o transporte intermodal foi competitivo, considerados os fretes utilizados, apenas para rotas que partiam do Estado em direção a São Paulo. Essas rotas percorriam distâncias superiores àquelas observadas dentro dos pares de origem-destino circunscritos aos limites do Paraná. Essas distâncias eram de 1.064 km, partindo de Foz do Iguaçu, e 855 km, de Pato Branco.

Dentro do modelo de racionalidade na utilização da infra-estrutura de transporte do Paraná, o quadro foi desfavorável ao transporte intermodal.

Por outro lado, o custo de transbordo, tido como importante elemento potencial na determinação da competitividade da intermodalidade, não alterou a classificação do transporte intermodal entre as alternativas investigadas, aos valores de US $\$ 1,50 / t$ e US $\$ 1,07 / t$. 


\section{NOTAS}

${ }^{1}$ As agroindústrias respondem por 33\% do PIB industrial do Estado, segundo a Gazeta Mercantil (1995).

${ }^{2}$ Conforme dados da Secretaria de Agricultura e Abastecimento, PR, da Associação Brasileira da Indústria de Óleos Vegetais (ABIOVE) e da Associação Brasileira da Indústria de Trigo (ABITRIGO) utilizados nesta pesquisa.

${ }^{3}$ Baseado na Tese de Doutorado em Economia Aplicada, defendida pelo primeiro autor na Escola Superior de Agricultura Luiz de Queiroz da Universidade de São Paulo (ESALQ/USP), sob orientação do segundo autor.

\section{ReFERÊNCIAS BibLIOGRÁFICAS}

BROOKE, A.;

KENDRICK, D.;

MEERANS, A.

GAMS. Washington : Gams

Development Corporation, 1996.

CONAB - COMPANHIA NACIONAL DE ABASTECIMENTO.

Previsão e acompanhamento de safras. ano 20, n. 5, jul. 1996.

FERRAZ, J. C.;

KUPFER, D.;

HAGUENAUER, L.

Made in Brazil : desafios competitivos para a indústria. Rio de Janeiro : Campus, 1995. cap. 3.

FIBGE - FUNDAÇÃO INSTITUTO BRASILEIRO DE GEOGRAFIA E ESTATÍSTICA.

Regiões de influência das cidades. Rio de Janeiro : FIBGE, 1987.
GAZETA MERCANTIL.

Paraná - balanço anual 1995/96. Curitba, ago. 1995. ano 2, n. 2, p. 6 .

GEIPOT - EMPRESA BRASILEIRA DE PLANEJAMENTO DE TRANSPOSTES.

Corredores de transporte : proposta de ações para adequação da infra-estrutura e para racionalização de transporte de granéis agrícolas. Brasília : Ministério dos Transportes/GEIPOT, 1997.

LIEB, R. C.

Transportation : the domestic system. Reston : Reston Publishing, 1978. cap. 7.

MAGALHÃES FILHO, F. B. B.

Oportunidades da agroindústria no Paraná. Revista Paranaense de Desenvolvimento, n. 41, p. 4560, mar./abr. 1974. 
MARTINS, R. S.

Racionalização da infra-estrutura de transporte no Estado do Paraná : o desenvolvimento e a contribuição das ferrovias para a movimentação de grãos e farelo de soja. Piracicaba, 1998. Tese (Doutorado) - Escola Superior de Agricultura Luiz de Queiroz, Universidade de São Paulo

MONTEIRO, N.

Parcerias para concluir a integração. Gazeta Mercantil, Curitiba, 22 dez. 1997. p. 9.

NOVAES, A. G.

Métodos de otimização : aplicações aos transportes. São Paulo : Edgard Blücher, 1978.
OLIVEIRA, J. C. V.

Análise do transporte de soja, milho e farelo de soja na hidrovia Tietê-Paraná. Piracicaba, 1996. Tese (Mestrado) Escola Superior de Agricultura Luiz de Queiroz, Universidade de São Paulo.

SECRETARIA DOS TRANSPORTES.

Paraná : logística e multimodalidade. Curitiba : SETR/PR, 1996.

WRIGHT, C. L.

Análise econômica de transporte e armazenagem de grãos : estudo do corredor de exportação de Paranaguá. Brasília : Ministério dos Transportes/GEIPOT, 1980. 